\title{
A Study on the Protection and Living Inheritance of Oroqen Nationality's Birch Bark Art from the Perspective of Intangible Cultural Heritage*
}

\author{
Xiaoli Zhang \\ College of Fine Art and Design \\ Heihe University \\ Heihe, China
}

\author{
Tianbao Yan \\ College of Fine Art and Design \\ Heihe University \\ Heihe, China
}

\begin{abstract}
New vitality will be injected into the heritage to achieve "living inheritance" of cultural heritage in the way of taking the birch bark art of the Oroqen nationality from the perspective of intangible cultural heritage, using the professional advantages of arts to develop and utilize cultural heritage, and using the help of the spread and promotion of cultural industries.
\end{abstract}

Keywords-intangible cultural heritage; Oroqen nationality; birch bark art; protection; inheritance

\section{INTRODUCTION}

The Oroqen nationality is one of the 56 nationalities in China. It is mainly distributed in the Oroqen Autonomous Banner, Zhalantun City, Moli Dawa Banner, Arong Banner in the northeast of Inner Mongolia Autonomous Region, Tahe, Huma, Xunke, Jiayin County and Heihe City in Heilongjiang Province. From the perspective of art, developing aesthetic elements that can be carried forward and used in the traditional skills of birch bark and displaying in a form that meets the modern lifestyle and aesthetic needs, is widely used in more intangible cultural heritage projects. Studying the process of birch bark products is of great significance for the intangible cultural heritage protection and living inheritance, and the promotion of minority arts and culture.

\section{RESEARCH ON THE BIRCH BARK ART OF THE OROQEN NATIONALITY}

Relevant Chinese research academic developments: Chinese studies on the protection and living inheritance of the birch bark art of the Oroqen nationality from the perspective of intangible cultural heritage can be roughly divided into four categories:

The first category is the study on the art history of the ethnic minority in the art of the Oroqen nationality, for example:

*Fund: The 2019 Heilongjiang Philosophy and Social Science Planning Project "Research on the Protection and Living Inheritance of Birch Bark Art of the Oroqen Nationality from the Perspective of Intangible Cultural Heritage", Project No.: 19YSE355
- The third chapter "Art History of Oroqen Nationality" of "China's Ethnic Minority Art History" (1995) chiefly edited by Wang Bomin

- "Art History of China's Ethnic Minority" (2001) chiefly edited by Chen Zhaofu and so on.

The second category is the study of the birch bark culture of the Oroqen nationality from the perspective of intangible cultural heritage, such as:

- Mo Hongwei, The Birch Bark Culture of the Oroqen Nationality. [J]. Heilongjiang National Series, 1997, (3);

- Sun Yidan, A Brief Talk on the Art of Oroqen Birch Skin Carving [J]. Art Research, 2005(01);

- Hanas, Oroqen Nationality Birch Bark Process [J]. Inner Mongolia Social Sciences, 1993 (01);

- Du Zhidong, Discussion on the Aesthetics of Oroqen Birch Bark Products [J]. Journal of Chifeng University, 2010(05).

The third category is the study on the artistic shape of birch bark of the Oroqen nationality from the perspective of intangible cultural heritage, such as:

- Tian Gang, The Animal Skin Culture and Birch Bark Culture of the Oroqen Nationality [J]. Education Exploration. 2004 (05);

- Wu Qiong. Study on the Decoration of Birch Bark Appliances of the Oroqen Nationality, Inner Mongolia [J]. Art Research, 2008;

- Hanas. On the Plastic Art of the Oroqen Nationality [J]. Inner Mongolia Social Sciences (Chinese version), 1998 (02);

- Compiled by Sun Yunlai, National Plastic Arts of Heilongjiang Basin [M]. Tianjin Ancient Books Publishing House. 1990, (34);

- Li Hongfu. Plastic Arts of Implements Made of Birch Barks of Chinese North Nationalities [J]. Journal of 
the Central University for Nationalities (Humane and Social Sciences Edition), 2003 (05).

The number of such studies is considerable and the studies are mature.

The fourth category is the study of the cultural inheritance and development of the intangible cultural heritage of the Oroqen nationality, such as

- Zhang Jingming, The Relationship between the Intangible Cultural Heritage Protection Countermeasures of the Art in the Northeast and Cultural Creative Industry [J]. Journal of Southern Yangtze University: Humanities \& Social Sciences Edition, 2013;

- Han Shuyun, Current Situation and Protection Countermeasures of Intangible Cultural Heritage in Oroqen [J]. Theoretical Research, 2009;

- Yu Mingshi, Inheritance and Development of the Oroqen National Culture: A Case Study of Shizhiteqi and Muku Hunter Villages in Tozamin Township [J]. Cultural Dialogue, 2013;

- Zou Ying, Research on the Protection and Inheritance of Oroqen Intangible Cultural Heritage [J]. Journal of Tibet Nationalities Institute, 2014;

- Zhang Xiufang, Discussion on the Inheritance of Birch Bark in the Oroqen Nationality [J]. History of Heilongjiang, 2013;

- Wen Zhu, Protection and Utilization of Intangible Cultural Heritage: A Case Study of the Oroqen Nationality [J]. Tourism Overview, 2013;

- Gong Rumin, Reflections on the Investigation and Protection of the Intangible Cultural Heritage in Oroqen [J]. Journal of Social Science of Jiamusi University, 2007;

- Zuo Xiuxian, Present Situation and Reflections on Minorities' Culture Industry Development in Heilongjiang Province [J]. Journal of Manchu Studies, 2012 ;

- Yu Fuye, Discussion on the Protection and Utilization of the National Grade Non- material Cultural Heritage of Oroqen Nationality in Heilongjiang Province [J]. Heilongjiang National Series, 2009;

- Xiang Hua, On the Protection, Passing Down and Inheriting of Intangible Cultural Heritage [J]. Heilongjiang National Series, 2011, etc.

Relevant foreign academic research trends are like follows: From the collection of existing literature in Russia, Mongolia, Canada and other countries, the development of birch bark has reached a certain depth. Foreign studies on birch bark culture and art are also quite rich, which mainly concentrated in Russia, Mongolia, Northern Europe and other countries. Many artists use birch bark as a material in their works. In contrast, foreign countries place more emphasis on birch bark art and their innovative development is more frontier than China. Although the translation materials are limited and related materials are relatively scarce, such documents as "Russian Folk Practical Art" and K. Xia Jiasi's "Documents of Birch Bark Unearthed in Mongolia" also fully show the results of such research.

\section{ACADEMIC AND APPLIED VALUES OF THE BIRCH BARK ART OF THE OROQEN NATIONALITY}

Intangible cultural heritage is a precious spiritual resource for mankind. The development and utilization of cultural heritage using the professional advantages of arts, and the promotion of cultural industries, can inject new vitality into the heritage, and realize the "living inheritance" of cultural heritage.

First, the traditional culture of ethnic minorities is an important part of China's intangible cultural heritage. In 2006 the craftsmanship of the production of birch bark was selected as the "First National Intangible Cultural Heritage List." However, the craftsmanship of birch bark has withstood the strong impact of modern civilization, and the problems of its protection and living inheritance need to be solved urgently. With the progress of the times and the change of production and lifestyle, birch bark products have come out of daily life and gradually become home displays and exhibits. Fewer people can make birch bark products .The craftsmanship of birch bark appliances is gradually declining. If not protected, it will be endangered.

Second, it is that Oroqen is one of the oldest nationalities in China. Their birch bark art is part of the outstanding historical and cultural heritage of the Chinese nation. It is not only a material cultural heritage, but also an important intangible cultural heritage. But its endangered production technology, profound graphic content, artistic form, and a handful of folk artists have been disappearing with the social and economic changes. It is urgent to strengthen national cultural concepts and protect national cultural heritage.

Third, it is the birch bark art of the Oroqen nationality from the perspective of intangible cultural heritage, which reproduces their living environment and is an embodiment of people's love for nature, respect for nature, and the pursuit of beauty, from which we can see the remains of ancient culture, To the rich aesthetic taste of the Oroqen people, the smart and hard-working Oroqen people carved colorful patterns on the clean birch bark with their hands, depicting the his process and sophisticated decoration methods fully demonstrated Out of Oroqen's simple aesthetics and primitive artistic pursuit, it has enriched the treasure house of folk art in the world and has high artistic value.

Fourth, the shape of birch bark products and the patterns and colors on the products are not only elegant and generous, but also have original style. From these craft products, people can not only see the unique hunting culture of the Oroqen in the sight of intangible cultural heritage, but also trace the trajectory of China's traditional culture. Therefore, it can be said with certainty that in the sight of intangible cultural heritage, the birch bark products of the Oroqen nationality are the carriers of China's ancient culture and therefore have great research value. 
IV. THE PROTECTION AND LIVING INHERITANCE OF BIRCH BARK ART OF THE OROQEN NATIONALITY FROM THE PERSPECTIVE OF INTANGIBLE CUlTURAL HERITAGE

The first is the ontological study of the birch bark art of the Oroqen nationality from the perspective of intangible cultural heritage.

- This part of study includes:

- The origin, development, and production of the birch bark art of the Oroqen nationality;

- The classification of decorative themes of the birch bark art of the Oroqen nationality;

- The forms of the birch art of the Oroqen nationality;

- The modeling characteristics of the birch art of the Oroqen nationality;

- The implied meanings of the birch bark art of the Oroqen nationality from the perspective of intangible Cultural Heritage.

The second is the problems that have faced in the protection and living inheritance of the birch bark art of the Oroqen nationality from the perspective of intangible cultural heritage.

The problems mainly include:

- Commercialization of styles and shrinking varieties;

- Changes in traditional production methods;

- Shortage of raw materials;

- The decreasing number of people who understand the national language;

- Fewer and fewer people who can make birch bark products;

- The declined production techniques of birch bark appliances.

The third is the countermeasures for the protection and living inheritance of the birch bark art of the Oroqen nationality from the perspective of intangible cultural heritage.

- The development and utilization of cultural heritage using the professional advantages of arts, and the promotion of cultural industries, can inject new vitality into the heritage, and achieve the "living inheritance" of cultural heritage;

- Quickly realizing the protection, census and selection of the inheritors, can make the inheritors receive state funding, pass on their skills to the next generation, and train new inheritors;

- In the cultural undertakings of the local government, it is necessary to encourage the protection of local folk customs;
- Through local education, making traditional culture a symbol of national self-esteem and self-confidence in the hearts of young people and the consensus of the next generation is the future of the heritage and development of national traditional culture;

- The birch bark art of the Oroqen nationality should be excavated and recorded as soon as possible under the sight of the ancient traditional intangible cultural heritage that is about to disappear.

\section{THE SIGNIFICANCE OF BIRCH BARK ART OF THE OROQEN NATIONALITY FROM THE PERSPECTIVE OF INTANGIBLE CULTURAL HERITAGE}

Firstly, it is to use the professional advantages of arts to develop and utilize cultural heritage. With the help of the cultural industry's dissemination and promotion, it is necessary to inject new vitality into the heritage and realize the "living inheritance" of cultural heritage.

Secondly, from the perspective of art, it is to develop aesthetic elements that can be carried forward and used in the traditional skills of birch bark and display in a form that meets the modern lifestyle and aesthetic needs, which can be widely used in more intangible cultural heritage projects.

Thirdly, it is to continuously develop and strengthen the cultural advantages of the Oroqen nationality, and try to inherit the birch tree culture of the nationality.

Fourthly, it is to discover the value of the traditional craftsmanship of the birch bark products of the Oroqen nationality through the traditions, history, and folklore of the nation.

\section{CONCLUSION}

It is necessary to take the realistic problem of the birch bark art in Oroqen as the starting point, take the protection of the intangible cultural heritage of birch bark art and the study of the living inheritance as the aim, and combine the normative and empirical studies. The inheritance of national culture, the pursuit of cultural diversity, and the avoidance of environmental assimilation can protect national cultural heritage and enhance understanding, identity and solidarity among nationalities. It also raises society's awareness of the traditional culture of the Oroqen nationality from the perspective of intangible cultural heritage, which can help the inheritance and promotion of the application of national culture in modern art.

\section{REFERENCES}

[1] Yan Tianbao, Zhang Xiaoli, An Analysis of Forming Factors of Color Characteristics in Traditional Oroqen Patterns [J]. Journal of Heihe University, 2019,10(06): 15-17. (in Chinese)

[2] Zhang Xiaoli, Liu Yang, Xu Ying, Research Status and Artistic Features of Rock Paintings in Heilongjiang River Basin [J]. Art Research, 2019(01): 4-6. (in Chinese)

[3] Zhang Xiaoli, Protection and Inheritance of Birch Bark Crafts of the Oroqen Minority in Heilongjiang Province [J]. Journal of Heihe University, 2017, 8(08): 5-6+29. (in Chinese) 